\title{
THE STRUCTURE OF DIDACTIC TRANSPOSITION CAPABILITY - ANALYSIS OF AN EXAMPLE OF DIDACTIC TRANSPOSITION OF PHYSICAL KNOWLEDGE IN THE TRAINING OF PEDAGOGICAL STUDENTS
}

\section{Tra Huong Do ${ }^{1,+}$, Van Thi Thanh Nguyen ${ }^{2}$}

\author{
Article History \\ Received: February 09, 2020 \\ Accepted: February 28, 2020 \\ Published: March 30, 2020
}

\section{Keywords \\ Didactic transposition, external transposition, internal transposition, capability, capability performance}

\author{
${ }^{1}$ Hanoi National University of Education, Vietnam; \\ ${ }^{2}$ Hung Vuong University, Vietnam \\ +Corresponding author •Email: dhtra@hotmail.com
}

\section{INTRODUCTION}

In order for knowledge of a subject to be teachable in schools, it is necessary to select, arrange and restructure it in a logical, purposeful link that can serve a definite teaching goal. There needs to be a "didactic transposition" (pedagogical transposition) so that students (Ss) could really acquire knowledge from the scholarly to general scientific one (knowledge of natural and social sciences). The transposition from scientific content to teachable one has its own rule. This "didactic transposition" contains not only the transition from scholarly knowledge to the knowledge to be taught, but also the transition from the knowledge to be taught to the teachable one in classrooms. This must ensure the freshness and topicality of science, and the teachable contents must simultaneously meet the requirements of training objectives and teaching purposes, in accordance with the circumstances and conditions of the country.

Moreover, the didactic transposition is also an important step in designing educational activities to achieve the goal of forming, developing competencies for students. The teacher is the key person who does the pedagogical transposition in educational and teaching activities in school. The transposition must be done in accordance with the time, space, subjects and students that the teacher is in charge (Do Huong Tra \& Tuong Duy Hai, 2016). Enabling students to convert scientific knowledge into subject knowledge in school is also one of the important tasks in the process of pedagogical training (Dinh Quang Bao et al., 2016). This also means that the pedagogical training process shall equip Ss with the capability of didactic transposition.

\section{LITERATURE REVIEW}

Research on the structure of didactic transposition capacity has been mentioned by several studies. These are 3 specific studies. First, Chevallard's (1985) research addressed the concept, the role of didactic transposition in general but not the didactic transposition of specific subjects. Develay's (1992) research also mentioned the didactic transposition scheme, where the transposition process consists of two main phases: the external didactic transposition the period of transition from knowledge to science and internal didactic transposition (internal transition between the knowledge to be taught and the knowledge taught in class). Philippe Perrenoud's (1998) study considers that the determination of the knowledge to be taught is based on the context, social needs, characteristics of the learners, etc. This is consistent with the idea that teaching is taught to learners, essential knowledge that learners can apply/ report and solve problems/ tasks in life, in professional practice.

From these studies, it is necessary to study didactic transpositions in specific subjects, as a basis to promote the capacity of didactic transpositions for future teachers. In fact, there are not many intensive studies on the didactic transposition capability in Vietnam. A few research works related to the capability of didactic transposition conducted by Tran Anh Dung (2013) or Nguyen Thi Thanh Van (2015) just refer to the concept of didactic transposition, links in the transition process, and some methods to train the capability of didactic transposition for Ss of Mathematics 
pedagogy in the process of teaching advanced geometry. However, those methods are not based on competence components or any performance criteria of competence components. This leads to many difficulties in evaluating the feasibility and effectiveness of those methods, and the results are not really convincing. Therefore, the researchers, through this article, would like to clarify the theories on the structure of didactic transposition including components of capability, capability elements and criteria to do didactic transposition via a case study with Physics.

\section{METHODS AND RESULTS}

\subsection{Research methods}

To deal with this task, we have conducted a theoretical study on didactic transposition (concept, stages of transposition), capability and structure of capability in general; explored the characteristics of Physics teaching, training teachers of Physics in Vietnam. Thereby, we have proposed the structure of didactic transposition for Ss of Physics pedagogy and studied an analysis sample of didactic transposition capability element.

\subsection{Research results and discussion}

\subsubsection{The concept of didactic transposition}

Didactic transposition (pedagogical transposition) is the work of transforming scholarly knowledge into the knowledge that needs to be taught in text-books, and then into the one that can be taught in classrooms. This transformation must ensure that the knowledge that needs to be taught and the knowledge that can be taught are consistent with the teaching purposes and the cognitive characteristics of learners. According to Develay (1992), the process of didactic transposition includes two stages, internal transposition and external transposition.

* External transposition is the stage in which scholarly knowledge (or expert knowledge) is transformed into the knowledge that needs to be taught (the knowledge identified in the school curriculum or manifested in textbooks). This stage is usually done by curriculum makers. At present, when Vietnamese schools are more self-reliant in program designing, teachers are the ones who do this work.

* Internal transposition is the stage in which the knowledge that needs to be taught is transformed into the one that can be taught in classrooms. The person who does this work is the teacher (lecturer, instructor) and pedagogical researcher. Based on the knowledge in curriculum, characteristics of learners and school conditions, a teacher can choose different paths of knowledge formation for learners. In this stage, there is a clear distinction between the transposition for learners who are the undergraduate and the transposition for those who are pupils.

In the process of training pedagogical students in general and students of Physics in particular, there are two chains of transposition. The first one is done by lecturers on learners who are pedagogical students. The second one is done by pedagogical students on learners who are pupils. These two chains also correspond to the current training context of pedagogical schools that are specialized in knowledge training (knowledge, skills in basic sciences) and professional knowledge (knowledge, skills in science education).

\subsubsection{The concept of didactic transposition capability}

In this research, the capability of didactic transposition (capability of pedagogical transposition) refers to the ability to analyze the transformation of scholarly knowledge into the knowledge that needs to be taught in textbooks and the transformation of the knowledge in textbooks into the one that can be taught in classrooms with a sense of responsibility, effectiveness under specific circumstances of the curriculum, which is based on the awareness and requirements of didactic transposition in accordance with the appropriate learners and school conditions.

However, it is not always easy for teachers and students of pedagogy to access to the original materials of scholarly knowledge, especially the very old claims of scientists in order to analyze the transition from scholarly knowledge to the knowledge that needs to be taught and then to the one that can be taught in classrooms. We would, therefore, note that the capability of didactic transposition of teachers (or students) is the ability to analyze the transformation of knowledge (manifested in books, textbooks (undergraduate level) and other sources) into the knowledge that needs to be taught in curriculum, school textbooks, and then into the knowledge that can be taught in classrooms with a sense of responsibility, effectiveness under specific circumstances of the curriculum, which is based on the awareness and requirements of didactic transposition in accordance with the appropriate learners and school conditions.

\subsubsection{The structure of didactic transformation capability}

Studies on capability agree that each capability consists of three main parts: i) Capability components describe one or more professional activities, demonstrating human potential abilities; ii) Capability elements are basic skills that constitute each component; iii) Criteria indicate the performance level of each element, often describing the results of actions, manipulations, indicators to be achieved, etc. 


\subsubsection{The capability of external transposition}

CET is the ability to analyze the transformation of knowledge (in books, textbooks (undergraduate level) and other sources) into the knowledge that needs to be taught in school curriculum and textbooks.

Based on the analysis of transposition chains done by pedagogical students, we suggest that the structure of the external transposition capability of pedagogical students consists of 4 elements and 13 criteria (Table 1).

Table 1. Elements and criteria of the external transposition capability

\begin{tabular}{|c|c|c|c|}
\hline \multirow{2}{*}{ No. } & \multicolumn{3}{|c|}{ Capability of external transposition } \\
\hline & Symbol & Elements & Criteria \\
\hline 1 & CET1 & $\begin{array}{l}\text { Analyze the knowledge of } \\
\text { different stages in the } \\
\text { transposition process }\end{array}$ & $\begin{array}{l}\text { Specify the knowledge level of the same type in school } \\
\text { curriculum and textbooks; } \\
\text { Compare the same type of knowledge presentations, the paths of } \\
\text { knowledge formation in the school curriculum and textbooks; } \\
\text { Explain the similarities and differences of the paths of } \\
\text { knowledge formation in school curriculum and textbooks. }\end{array}$ \\
\hline 2 & CET2 & $\begin{array}{l}\text { Analyze the objectives, } \\
\text { knowledge contents in } \\
\text { textbooks }\end{array}$ & $\begin{array}{l}\text { Identify the type of knowledge in textbooks; } \\
\text { Analyze the content objectives in school textbooks; Analyze } \\
\text { the content features in school textbooks. }\end{array}$ \\
\hline 3 & CET3 & $\begin{array}{l}\text { Analyze the diagram of the } \\
\text { scientific process of } \\
\text { developing and applying } \\
\text { knowledge }\end{array}$ & $\begin{array}{l}\text { Analyze the path of knowledge formation on physical phenomena; } \\
\text { Analyze the path of knowledge formation on physical quantities; } \\
\text { Analyze the formation of the laws of physics; } \\
\text { Analyze the formation of physics theories; } \\
\text { Analyze the trajectory of teaching the technical applications in } \\
\text { physics. }\end{array}$ \\
\hline 4 & CET4 & $\begin{array}{l}\text { Point out the applications } \\
\text { of knowledge in } \\
\text { engineering and in practice }\end{array}$ & $\begin{array}{l}\text { Point out the applications of physical knowledge in } \\
\text { engineering and in practice. } \\
\text { Indicate the roles of physical knowledge in other subjects. }\end{array}$ \\
\hline 5 & CET5 & $\begin{array}{l}\text { Restructure the knowledge } \\
\text { content in textbooks }\end{array}$ & $\begin{array}{l}\text { Indicate the improper presentation of knowledge in current } \\
\text { textbooks (if any). } \\
\text { Propose a different structure of knowledge content from } \\
\text { textbooks. }\end{array}$ \\
\hline
\end{tabular}

In comparison with the criteria in Table 1, the practical training at many pedagogical universities indicates that students are not yet interested in practicing skills of analyzing knowledge at different stages of the transposition. In addition, not all students of physics pedagogy have successfully analyzed the objectives, content characteristics, and knowledge formation in textbooks - even with students who have been equipped with teaching methodology. One of the reasons is that the time devoted to subjects constituting the elements of external transposition (such as the module Analysis of School Curriculum). Moreover, if students only have access to the analysis of teaching objectives, content characteristics, the path of knowledge formation in the textbooks until their third year or fourth year, the efficiency of practicing these skills will partly be affected. This is the time when students have gradually forgotten the relevant knowledge they have learned in general modules (Mechanics, Thermology and Molecular Physics, etc.); therefore, it is difficult to see the intimate connection between general knowledge and professional knowledge.

In addition to the applications of the physical knowledge presented in textbooks, it is necessary for pedagogical teachers/ students to explain other applications of physical knowledge in practice or in other fields (element CET4), for knowledge never stands alone but exists in the connection with other knowledge. This also increases the ability to integrate different types of knowledge to solve the problem of the teachers and students themselves. Then, based on such skills as CET1, CET2, CET3, CET4, students can recognize inappropriate points in the knowledge presentation of current textbooks so that they can propose another way to present the knowledge content. CET5 can be considered the highest rated element in the capability of external transposition.

\subsubsection{Capability of internal transposition}

CIT is the ability to transform the knowledge that needs to be taught into the one that can be taught in classrooms with a sense of responsibility, efficiency under specific circumstances of the curriculum, which is based on the awareness and requirements of didactic transposition in accordance with the appropriate learners and school 
conditions. We suggest that the structure of the internal transposition capability of Physics pedagogy students include 4 elements and 13 criteria (Table 2).

Table 2. Elements and criteria of the internal transposition capability

\begin{tabular}{|c|c|c|c|}
\hline \multirow{2}{*}{ No. } & \multicolumn{3}{|c|}{ Capability of internal transposition } \\
\hline & Symbol & Elements & Criteria \\
\hline 1 & CIT1 & $\begin{array}{l}\text { Determine the appropriate } \\
\text { targets of capacity } \\
\text { development for learners }\end{array}$ & $\begin{array}{l}\text { - Establish a goal in a certain topic/module at different } \\
\text { levels of awareness; } \\
\text { - Determine the skills that need obtaining in a lesson; } \\
\text { - Identify the attitudes needed in a lesson. }\end{array}$ \\
\hline 2 & CIT2 & $\begin{array}{l}\text { Utilize knowledge that } \\
\text { ensures the instructional } \\
\text { objectives }\end{array}$ & $\begin{array}{l}\text { - List the knowledge related to the objective; } \\
\text { - Simplify and shorten teaching content horizontally (range } \\
\text { of the learners); } \\
\text { - Simplify and shorten teaching content vertically (levels of } \\
\text { difficulty for learners). }\end{array}$ \\
\hline 3 & CIT3 & $\begin{array}{l}\text { Design lesson plans that meet } \\
\text { the instructional objectives }\end{array}$ & $\begin{array}{l}\text { - Identify the logic that shapes the knowledge content; } \\
\text { - Identify learning situations that correspond to the logic of } \\
\text { knowledge content; } \\
\text { - Select suitable instructional forms and method with the } \\
\text { knowledge content; } \\
\text { - Select suitable forms of revising, summarizing, testing, } \\
\text { and evaluating after class. }\end{array}$ \\
\hline 4 & CIT4 & Conduct the lesson plans & $\begin{array}{l}\text { - Conduct the instruction in class step by step as scheduled; } \\
\text { - Be flexible in organizing learning activities; } \\
\text { - Assess the students' knowledge, skills, and abilities in class. }\end{array}$ \\
\hline
\end{tabular}

- Determining the goal of developing the appropriate capability for learners: The determination of the instructional objectives for lessons in current textbooks is often assisted with the standard knowledge, skills, or teacher's book, etc. However, with the instructional topics that do not belong to any specific lesson in current textbooks, students will be trained to compose the instructional objectives (knowledge, skills, and attitudes) that they will achieve through those topics. When determining the knowledge objectives, students should pay attention to the expression of the cognitive levels through words that can be measured and evaluated. Normally, cognitive levels are written in Bloom's cognitive scale with three basic levels - knowledge, understanding and application.

- The mobilization of knowledge to ensure the instructional goals requires students to remove old information, update the new one, detect and deal with contents, exercises, questions in the textbooks that do not match the educational objectives of the program or those that require too much knowledge in-depth, not consistent with the cognitive and physiological age of the learners. For practical issues that require knowledge acquisition from a variety of sources, students should know how to "simplify and shorten" the knowledge contents both horizontally and vertically. This is not an easy thing to do, especially the content with mathematical elements as well as knowledge related to many new concepts.

- Designing lesson plans based on the objectives: This work does not follow any available model but it is based on the issues of teaching methodology, the path of knowledge formation that students of Physics pedagogy must identify the cognitive process in acquiring and applying knowledge; clarify learning situations that correspond to the logic of knowledge contents. Learning situations must promote the interaction between learners and learners, teacher and learners.

- Conducting the lesson plans also has different levels. Students may design a good lesson plan but it is not easy to conduct those, especially the flexibility in organizing learning activities and assessing students' ability in classrooms.

3.2.4. Case studies on the didactic transposition capability in Physics

The case studies were tested with a group of 10 teacher students. These are the third year students who are studying "Analysis of the General Physics Program". We, herein, analyze the element CET1 in the external transposition capability of the Physics pedagogy students. In order to practice this skill, from the selected knowledge, students should take the following steps:

Step 1: Locate the knowledge in different types of documents. In this step, it is possible for students to locate the knowledge in the curriculum and current textbooks. Indicating the location of the knowledge in various documents helps 
students have an overview of knowledge, logic of developing the same kind of knowledge with different learners. After locating the knowledge, students should also make comments and comparisons on the results obtained. Experimental results showed that 8 out of 10 students could not identify inadequate knowledge. Especially, students did not recognize all the knowledge-based lessons in the textbook.

Step 2: Determine the type of knowledge contents presented in the curriculum and textbooks. 6 out of 10 students did not identify the right type of knowledge content. In order to perform this, students should relate the knowledge properties under the view of teaching theories to determine whether knowledge belongs to the concepts, phenomena, laws, theories or applications of Physics. Students can, thereby, learn how the knowledge properties are reflected in the curriculum and textbooks.

Step 3: Compare the level of knowledge contents between curriculum and textbooks. Based on the knowledge properties mentioned in step 2, students need to compare and assess the level of knowledge content. Students can create tables to show the combination of knowledge content and its levels. This step is also important for students to implement "objectives analysis, knowledge properties in textbooks" (capability component TEC2).

However, only 5 out of 10 students performed well. All of these 5 students are among 6 students who performed well in step 2. Thus, initial results showed that the type of knowledge content in step 2 was closely related to the comparison, assessment of the knowledge level in step 3.

Step 4: Indicate the knowledge presentation and formation in different documents. The demonstration of knowledge required students to be capable of generalization and they could only perform well when the knowledge is fully located. 6 out of 8 students who performed well step 1 , successfully completed the tasks in step 4 . The analysis of knowledge formation in different documents should be based on the formation of specific knowledge of physics. When analyzing how knowledge is presented in textbooks, students have found that the logic that forms the same knowledge could possibly follow different paths.

For example, the path that generates the concept of physical quantities usually consists of five typical stages, respectively: qualitative characteristics, quantitative characteristics, conceptual definitions, unit of measurements identification, and application of the concepts in practice. However, this order is not always fixed. Some can be changed with others; for instance, quantitative characteristics can be done before qualitative characteristics.

When analyzing the formation of a physical knowledge, students can not only identify the stages of knowledge formation, but also describe how each of those stages is presented in the syllabus and textbook. This creates a good premise for students to carry out the "Diagram analysis of the process of building and applying scientific knowledge".

Step 5: Demonstrate the differences in the levels of knowledge content, knowledge presentation and formation. In this step, students should focus on answering such questions as: Why is the knowledge formed in that way? Why is there a difference in the levels of knowledge? What are the advantages and disadvantages for learners from those different presentations?

We shall illustrate via a sample analysis of the knowledge about "gravity" in different stages of the transposition: We, herein, select the mechanics textbook (Dao Van Phuc \& Pham Viet Trinh, 1990) one of the basic books used in many pedagogical schools in Vietnam and the current textbook Physics Grade 10 (Standardized). When analyzing the knowledge of gravity, applying the above steps, the results from students are shown as follows:

- Locations of "gravity" knowledge in different documents are shown in Table 3:

Table 3. Locations of "gravity" knowledge in different documents

\begin{tabular}{l}
\hline Mechanics textbook \\
$\begin{array}{l}\text { Chapter IV: Gravitational field (The law of universal } \\
\text { gravitation; Gravitational mass and inertial mass; }\end{array}$ The law of universal gravitation). \\
Gravitational field; Gravitational potential energy; \\
Motion in gravitational field. Kepler's laws; How fast \\
the Earth travels in the universe)
\end{tabular}


* Physics Grade 10 textbooks: - Gravity is explored in the chapter of particle dynamics and conservation laws. It is considered one type of mechanical force and only applied for particle or spherical objects that have uniformly distributed mass; - The content and the knowledge levels of "gravity" in the Mechanics textbook and Physical Grade 10 are shown in Table 4:

Table 4. The content and the knowledge levels of "gravity" in the Mechanics textbook and Physical Grade 10

\begin{tabular}{|c|c|c|}
\hline $\begin{array}{c}\text { Knowledge } \\
\text { content }\end{array}$ & Mechanics textbook & $\begin{array}{l}\text { Physics Grade } 10 \text { - } \\
\text { Standardized }\end{array}$ \\
\hline
\end{tabular}

Qualitative A force of attraction that exists between all objects, characteristics everywhere in the universe

Every object in the universe attracts each other with a force called gravity.

Between any two particles, with masses $\mathrm{m}_{1}$ and $\mathrm{m}_{2}$, separated by a distance $r$, there exist gravitational forces

Quantitative $\overrightarrow{\mathrm{F}}_{21}$ and $\overrightarrow{\mathrm{F}}_{12}$ from one particle to another, the force The gravity between any two objects (considered as particles) is directly proportional to the characteristics intensity is directly proportional to the product of $\mathrm{m}_{1}$ and $\mathrm{m}_{2}$, and inversely proportional to the square of the distance between them.

product of their masses, and inversely proportional to the square of the distance between them.

Expressions are written in algebraic and vector forms:

+ Algebraic form: $F_{21}=F_{12}=G \frac{m_{1} m_{2}}{r^{2}}$ $F_{h d}=G \frac{m_{1} m_{2}}{r^{2}}$

Expressions

+ Vector form: $\vec{F}_{12}=-G \frac{m_{1} m_{2}}{r_{12}^{3}} \vec{r}_{12}$

$\mathrm{G}=6,67 \cdot 10^{-11} \mathrm{~N} \cdot \mathrm{m}^{2} / \mathrm{kg}^{2}$ is the gravitational constant

+ Particles

+ Objects that are small compared to the distance between them.

Applicable + Spherical homogeneous objects.

conditions - If two objects whose sizes cannot be ignored compared to the distance between them, then:

The distance between two objects is immense compared to their sizes;

+ Spherical homogeneous $\vec{F}_{12}=-\sum_{i}^{n_{1}} \sum_{j}^{n_{2}} G \frac{m_{i} m_{j}}{r_{i j}^{3}} \vec{r}_{i j}$

objects.

- The concepts of gravitational mass and inertial mass are mentioned:

+ A mass that is determined by the acceleration of the

Gravitational object under the effect of the force $\mathrm{F}$ is called the inertial mass and inertial mass mass.

+ A mass that is determined by the strength of the gravitational force is called gravitational mass. It is impossible to distinguish between gravitational mass and inertial mass.

Consider the gravitational field in general and the gravitational field of the Earth:

- Any object creates a field around it called gravitational field.

Gravitational

- The gravitational field of each object is independent field from the presence of other objects

- The intensity of gravitational field of $m_{2}$ at $m_{1}$ : $\vec{g}=-\frac{G m_{2}}{r_{12}^{3}} \vec{r}_{12}$.

- Gravitational field of the Earth:
- Not gravitational mass or inertial mass, but the mass itself is considered the quantity that characterizes the inertia of the object.

- Gravity is the particular case of gravitational force. (Gravity on an object is roughly understood as the Earth's gravitational force on that object).

- There exists a gravitation field surrounding the Earth. The manifestation of gravitation field is the gravitational force on an 
+ The Earth's gravitational fields is also called gravity or gravitation field

+ The intensity of gravitation field is the gravitational acceleration/ free-fall acceleration of an object on Earth.

Gravitational potential energy

Overview of gravitational potential energy:

- If we choose the root of potential energy at infinity, the potential energy of a random point $\mathrm{P}$ is calculated as follows: $E_{t P}=-\frac{G M m}{r_{P}}$

The potential energy at infinity has the greatest algebraic value. To put things away, the external force has done positively, the system receives more energy.

- If the potential energy is on the ground surface, $E_{t}=$ $\mathrm{mgh}, \mathrm{h}$ is the height of the object $\mathrm{m}$ from the ground surface.

- Consider the motion of objects (celestial bodies, artificial satellites) in the gravitational field in general, and separately investigate the motion of artificial satellites orbiting around the Earth. object with the mass $m$ located at any point in the gravitation space.

Consider the potential energy of gravitation field:

- The potential energy of gravitation field of an object is a type of energy that interacts between the Earth and the object; it depends on the location of the object in gravitation field.

- When an object with the mass $m$, and the height $\mathrm{z}$ from the earth surface (located in the Earth's gravitation field), the gravitation potential energy of that object is defined by the formula: $\mathrm{W}_{\mathrm{t}}=\mathrm{mgz}$.

- Do not consider the specific motion of objects in the gravitational field.

As can be seen from Table 4, the knowledge of gravity is fully explored in the Mechanics textbook (from the concept of gravitation to the specific types of energy for this kind of interaction-gravitational potential energy and in the special case of gravitation potential energy). Although the relevant practical issues are not directly presented, learners will also have to find out by themselves if gravity has influence in life and technology. The approach to gravitational mass and inertial mass is presented, and then the conclusion that there is no distinction between these two masses is because the "inertial" attribute and the "gravitational" attribute of an object are related.

The students analyzed: In the Physics Grade 10 textbooks, the knowledge levels of gravity are quite similar in qualitative characteristics, quantitative characteristics, expressions, and application conditions. The standardized version does not mention the orbiting motion of planets in the Solar system. This leads to the fact that many learners do not know the form of their orbits, and are unaware of the inventors of those motions; considering gravity as the particular case of gravitational force neglects the effect of the rotation of the Earth. The standardized versions refer to the mass that characterizes the inertial level without mentioning the gravitational property of the object.

In the Mechanics textbook, considering gravitational field in general, it is advantageous that learners will learn that there exists a field of force surrounding any object, whereas the school textbooks only introduce gravitation as a special case of gravitational field. This leads to incomplete understanding of the gravitational field of objects among learners, especially when considering the gravitational field of other planets in the Solar system.

- The knowledge presentation and the knowledge formation of "gravity" in textbooks are shown in Table 5:

Table 5. The knowledge presentation and the knowledge formation of "gravity"

\begin{tabular}{|c|c|}
\hline Mechanics textbook & Physics Grade 10 - Standardized \\
\hline 1. Knowledge presentation & \\
\hline $\begin{array}{l}\text { - Issues related to gravity are } \\
\text { presented in one chapter } \\
\text { - The knowledge of gravity is } \\
\text { presented after the studies on } \\
\text { particle kinematics, particle } \\
\text { dynamics, dynamics of mechanical } \\
\text { systems, and conservation laws in } \\
\text { mechanics. }\end{array}$ & $\begin{array}{l}\text { Two issues related to gravity (gravity, the law of } \\
\text { universal gravitation and gravitation potential } \\
\text { energy) are presented in two different chapters: } \\
\text { - Gravity, the law of universal gravitation are } \\
\text { presented in the chapter of particle dynamics. } \\
\text { - Gravitation potential energy is presented in the } \\
\text { chapter of conservation laws. } \\
\text { - How Newton verified the law of universal gravitation } \\
\text { is mentioned in the section "Do you know?" }\end{array}$ \\
\hline
\end{tabular}




\begin{tabular}{|c|c|c|}
\hline \multicolumn{3}{|c|}{ 2. The knowledge formation } \\
\hline $\begin{array}{l}\text { Detecting } \\
\text { qualitative } \\
\text { characteristics }\end{array}$ & $\begin{array}{l}\text { - Provide qualitative characteristics } \\
\text { in the form of overview of the } \\
\text { research results of scientists. } \\
\text { - Introduce the history of finding the } \\
\text { law of universal gravitation. }\end{array}$ & $\begin{array}{l}\text { - To give learners first impressions about gravity, } \\
\text { teacher can introduce the apple-drop event, which } \\
\text { helped Newton find the law. }\end{array}$ \\
\hline $\begin{array}{l}\text { Detecting } \\
\text { quantitative } \\
\text { characteristics }\end{array}$ & $\begin{array}{l}\text { - The quantitative characteristics } \\
\text { with many directions, locations and } \\
\text { magnitude of gravity are included } \\
\text { in the content of the law. } \\
\text { - Statement of the law for the case } \\
\text { of two particles. }\end{array}$ & $\begin{array}{l}\text { - Quantitative characteristics are stated in form of } \\
\text { law. } \\
\text { - Expression is written in the form of force } \\
\text { magnitude. } \\
\text { - State the conditions for the application of law in the } \\
\text { cases of two particles and two homogeneous spheres. }\end{array}$ \\
\hline $\begin{array}{l}\text { Definition, concept, } \\
\text { and unit of } \\
\text { measurement }\end{array}$ & $\begin{array}{l}\text { Do not indicate the definition and } \\
\text { how to determine the unit of } \\
\text { measurement }\end{array}$ & $\begin{array}{l}\text { Do not indicate the definition and how to determine } \\
\text { the unit of measurement }\end{array}$ \\
\hline Application & $\begin{array}{l}\text { - Apply the law of universal } \\
\text { gravitation to particles, and the } \\
\text { principle of superposition of forces } \\
\text { for two objects. } \\
\text { - The concept of gravitation } \\
\text { continues to be improved and } \\
\text { expanded in the lesson } \\
\text { Gravitational Field, Gravitational } \\
\text { Potential Energy, and Motion in the } \\
\text { Gravitational Field. }\end{array}$ & $\begin{array}{l}\text { - Consider the gravity of the Earth. Build the } \\
\text { expression of free-fall acceleration. } \\
\text { - The concept of gravitation continues to be fulfilled } \\
\text { in the chapter of Conservation Laws (Unit } 26 \text { - } \\
\text { Potential energy). } \\
\text { The gravitation potential energy is reported, along } \\
\text { with the data provided by the teacher, the } \\
\text { explanations. Then the relationship between the } \\
\text { potential energy variation and the work of gravity is } \\
\text { presented. }\end{array}$ \\
\hline
\end{tabular}

The students commented: From Table 5, we can see that the knowledge presentation of gravity in the Mechanics textbook helps learners have a fairly complete understanding of gravity. The presentation in the Physics Grade 10 textbooks may make the learners think that there is little relation between gravity and gravitation potential energy. However, it is close to the cognition of learners. It is consistent with the logic of teaching learners about the particle dynamics. This chapter helps learners understand that force is the cause of motion, and one of the most common mechanical forces is gravity. The introduction of knowledge concerning the motion of satellites into the chapter of conservation laws is also valid because the chapter examines the energy and the transformation law of energy forms. To operate satellites, it requires an understanding of the energy that needs to be provided initially so that it can work, and that energy needs to be calculated based on an understanding of gravitation potential energy and kinetic energy.

The knowledge formation of "gravity" is different from the common five-stage process. The detection of quantitative characteristics of concepts does not derive from qualitative characteristics but occurs simultaneously with the laws of physics (the law of gravity shows the relation between the gravitational magnitude and mass objects' volumes and the distance between them). There is no conceptual definition like "concept to be defined = concept of species + intrinsic attributes of species" or describing the whole qualitative and qualitative characteristics of the concept. The measurement unit of gravity that students have learned in Grade 8 is not defined here. The application of concepts in practice mentioned in the mechanics textbook is fairly sufficient; however, it is only the generalization and extension of the concept, while the content in Physics textbook clarify the knowledge that students have learned before (acceleration of gravity, gravitational knowledge) and become more complete in the Law of Conservation chapter.

Students explained the transfer of knowledge: The difference in knowledge level, knowledge presentation and the scientific process of knowledge formation of gravity can be demonstrated to learners as follows:

For high school students, they have not learned much about mathematical knowledge (vectors, integrals, differential equations, etc.) so they cannot acquire the pure knowledge by theory. With the knowledge of excessive use of mathematics (setting the equation of gravity), students are informed of the expression at the end of the lesson. Besides, the objective of knowledge achievement when considering the mechanical motion and the cause of the motion is simply knowing the cause that keeps the Earth as well as other planets orbiting around the Sun is gravity; therefore, students just can state (at recognition level) the content of the law, write the expression of gravity and potential energy. They just 
need to learn that gravity is proportional to what elements, thereby infer the role of gravity in nature like manufacturing artificial satellites, etc. The arrangement of the two knowledge contents in two different chapters will enable students to access the knowledge because it is not too different from the knowledge that they have learned before.

The difference in the presentation of the standardized and advanced books is due to the difference in the objectives for the learners of those programs. Although the experiment was conducted with 10 students, the initial results showed that the determination of the capability components of the didactic transposition was necessary for students to perform the analysis and comparison of knowledge presentation in the General Physics curriculum and textbook. In other words, this helped develop the external the didactic transposition capability for students.

Indicating these capability elements has help learners better understand the relationship between general knowledge and knowledge in textbook, understand how the instructional contents (knowledge) in textbooks have been reduced and simplified both in with and in depth in comparison with the same knowledge presented in the curriculum at the undergraduate level. Students are aware of the reason why knowledge is arranged in that way. This also gives them opportunities to recognize the inadequateness in knowledge presentation so that they can rearrange it in a more appropriate way. Moreover, it also helps students to clearly identify the logic of knowledge formation so that they can design appropriate learning situations to actively acquire knowledge.

\section{DISCUSSION AND CONCLUSION}

The awareness of the structure of didactic transposition capability of the Physics pedagogy students would be helpful for us in further research to investigate and evaluate the didactic transposition capability of the Physics pedagogy students, the didactic refinement of didactic states for physics students at pedagogical universities, the reality of training the didactic transposition capability for the Physics pedagogy students. These are also the bases for us to design training contents, training schedules and appropriate tools to assess the didactic transposition capability of the Physics pedagogy students at different levels.

\section{REFERENCES}

Chevallard, Y. (1985). La transposition didactique du savoir savant au savoir enseigné. Grenoble: Editions Pensée Sauvage.

Chevallard, Y. (1989). On didactic transposition theory: Some introductory notes. In the proceedings of The International Symposium on Selected Domains of Research and Development in Mathematics Education, 51-62.

Develay, M. (1992). De l'apprentissage à l'enseignement. Paris: ESF éditeurs.

Dinh Quang Bao et al. (2016). Teacher training program to meet the requirements of general education reform. Hanoi University of Education Publishing House.

Do Huong Tra \& Tuong Duy Hai (2016). Orientation of some integrated teaching methods via analyzing the potentials in organization and implementation. Journal of Science, Hanoi University of Education, 4, 43-50.

Johsua, S. \& Dupin, J. J. (1993). Initiation à la didactique des sciences et des mathématiques. PUF, Paris.

Joshua, S. (1997). Le concept de Transposition Didactique peut-il étendre sa portée au delà de la didactique des sciences et des mathématiques? PUF, Paris.

Nguyen Thi Thanh Van \& Do Huong Tra (2016). Proposing a process of training didactic transposition capability for students in the training process at pedagogical universities. Journal of Science, Hanoi University of Education, 61(8B), 170-178.

Nguyen Thi Thanh Van (2015). Teaching advanced geometry in university towards the preparation for capability of teaching geometry in high school. $\mathrm{PhD}$ dissertation in Educational Science.

Perrenoud, P. (1998). La transposition didactique à partir de pratiques : des savoirs aux compétences. Revue des Sciences de l'éducation, 24(3), 487-514.

Tran Anh Dung (2013). Teaching the concept of continuous function in high school. $\mathrm{PhD}$ dissertation in Educational Science.

Vellopoulou, A. \& Ravanis, K. (2010). A methodological tool for approaching the didactic transposition of the natural sciences in kindergarten school: the case of the "states and properties of matter" in two Greek curricula. Review of Science, Mathematics and ICT Education, 4(2), 29-42.

Weiner, F.E. (2001). Comparative performance measurement in schools. Weinheim and Basejl: Beltz Verlag, 17-31. 